\title{
Introduction to the special series-behavioral medicine at 40: origins, achievements, and future directions
}

\author{
John M. Ruiz ${ }^{1}$ Christopher R. France ${ }^{2}$
}

Published online: February 5, 2019

(C) Springer Science+Business Media, LLC, part of Springer Nature 2019

\begin{abstract}
The Journal of Behavioral Medicine emerged 40 years ago as a part of a concerted effort to promote a greater understanding of health and illness through the integrated lenses of behavioral and biomedical sciences. The aim of this special series is to commemorate the 40th anniversary of the Journal of Behavioral Medicine through state-of-the-science reviews synthesizing the origins, evolution, current status, and future directions of key aspects of the field. In this introduction, we outline the impetus for this special series and highlight the key themes across the included papers.
\end{abstract}

Keywords Behavioral medicine $\cdot$ Health psychology

Biopsychosocial $\cdot$ Anniversary

Forty years ago Star Wars and Grease were the top movies, most people listened to music on vinyl or 8-track tapes, it had been less than 10 years since man had first stepped on the moon, Space Invaders ignited the videogame craze, disco was alive and well, and the Journal of Behavioral Medicine was launched. In 1977, the year before this journal's inception, George Engel published his seminal paper proposing the biopsychosocial model as a more

Special thanks to Dr. Alan Christensen for affording us this editorial opportunity and to the many scientists who preceded the field, contributed to its genesis, and who will bring us the next advances.

John M. Ruiz

JohnRuiz@email.arizona.edu

1 Department of Psychology, University of Arizona, 1503 E. University Blvd, PO Box 210068, Tucson, AZ 85721, USA

2 Department of Psychology, Ohio University, Athens, OH, USA ecologically valid approach to understanding health and illness through the integrated lenses of behavioral and biomedical sciences. The model challenged the 300 year dominance of mind-body dualism and offered an alternative explanation to illness beyond dogmatic biological reductionistic philosophy. After four decades, these ideas have gone from radical (and somewhat heretical) to common sense and common science.

The genesis of the field of behavioral medicine was an evolutionary step in the broader science of medicine; a predictable development to further understanding of the determinants of disease and to identify pathways to reduce suffering and related disability. Incorporating human experience by the identification of psychological and social factors into the modeling of health represented a seismic paradigm shift in wellness conceptualization with implications for a fundamentally new approach to the study and practice of medicine. To support this emerging field, a professional scientific infrastructure was created to identify priorities, provide funding, facilitate the development of investigative tools, foster mechanisms for critical evaluation, and to disseminate and implement findings. Four decades in, the science and profession of behavioral medicine has evolved into a robust field with enormous potential to help understand and improve human health and wellbeing.

\section{Overview of special series}

To commemorate this anniversary, we offer this special series to highlight the scientific and professional achievements of the field. The solicited papers address key factors that have contributed to behavioral medicine's foundation as a scientific discipline including its origins and history, 
the evolution of its scientific contributions, and the development of an infrastructure to identify priorities, provide for financial support, optimize investigations through peerreview, disseminate findings, and to train a multidisciplinary and diverse workforce. We are fortunate in that many of the topics are addressed by visionaries who helped launch the field and who have contributed significantly to its continuing development.

\section{Origins and history}

The Journal of Behavioral Medicine emerged as part of the infrastructure to disseminate and promote behavioral medicine scientific advances. Fittingly, the first paper in the first issue was titled, "Yale Conference on Behavioral Medicine: A Proposed Definition and Statement of Goals." Written by Drs. Gary Schwartz and Steve Weiss, the paper was one of a series of burst publications describing the seminal conference and formally introducing the scientific community to this new multidisciplinary field. In this special series, these two founding fathers revisit that era and provide a narrative account of behavioral medicine's origins, their vision at that time, and their perspective on where the field is going (Weiss \& Schwartz, 2019). This longitudinal account offers readers a unique behind the scenes perspective of the field's origin story from some of two of its creators. In his complementary piece, Dr. Ken Wallston (2019), the academician and long-time behavioral medicine historian, describes the broader evolution of the field. Dr. Wallston's paper focuses on the original aspiration for a multidisciplinary field, the subsequent disproportionate representation of health psychology as a discipline within the behavioral medicine universe, and potential avenues for fostering greater disciplinary balance. Current Journal of Behavioral Medicine Editor-In-Chief, Dr. Alan Christensen's (2019) contribution extends this historical theme by describing the role of this journal as a critical platform for the dissemination of peer-reviewed research; from that first paper defining the field to contemporary advances. Together, these papers describe the development of the field not as a rival to medicine as it is often characterized, but rather as an evolutionary step in the science and practice of medicine.

\section{Scientific justification: from risk identification to intervention implementation}

Central to the establishment of behavioral medicine as a science is to move the hypothesis of psychosocial risk from folklore to fact. From early conceptions of stress-related illness to contemporary epigenetics, the science of psychosocial risk is predicated on the idea that psychological and social factors are inextricable to understanding physical health and wellbeing. In their paper, Drs. Schneiderman, McIntosh, and Antoni (2019) provide a history and benchmark of evidence regarding this relationship. As these authors note, the evidence includes not only prospective observational data on candidate psychosocial factors and disease development but also work showing that addressing lifestyle factors reduces risk. These observations not only support the biopsychosocial model as an important predictive tool but also as a framework for identifying modifiable targets for risk reduction with hard outcome advantages.

Establishment of psychosocial influence on disease risk and management is the bedrock of the field but only a first step in the higher priority of improving human physical health and well-being. Translation of evidence to interventions that are scalable is critical. Rapid technological advances over the last few decades afford intervention scientists with opportunities the founding fathers likely could not envision. Dr. Arigo and colleagues (2019) describe how technology is facilitating broader, more responsive outreach, in a manner that is scalable and more cost effective than traditional face-to-face interventions. The use of mobile phones, social networking platforms, and other digital technologies are improving not only the reach of behavioral medicine interventions but also the potential for greater connection between patient and provider. And despite a myriad of challenges, these advances are creating new professional partnerships that may revolutionize the delivery of healthcare with behavioral medicine at the forefront.

Beyond direct patient interventions, behavioral medicine also has an enormous potential to improve population health by informing public policy. Lifestyle behaviors and behavioral opportunities are largely set within public policy parameters, with prominent examples over the last few decades including evolutions in policy regarding drinking age, smoking zones, and use of marijuana. In her paper, Dr. Karen Emmons (2019) describes why behavioral medicine should pursue involvement in policy making as a means to population-level health prevention and disease management. She notes that involvement can range from local (e.g., institutional) to broader city, county, state, and national policy. Consistent with a social ecological framework, this paper reminds us that individuals exist in levels of interrelated social contexts and that interventions at any one level can influence the health outcomes at the others. This affords behavioral medicine multiple pathways for improving the health of individuals and the social networks they inhabit. 


\section{The scientific infrastructure}

Discovery and implementation science are contingent on a professional infrastructure to support the work. The past 40 years have seen the development of the profession of behavioral medicine from idea to a robust enterprise. With his pre-existing role in the National Institutes of Health (NIH), Dr. Steve Weiss and others were critical to the early embedding of behavioral medicine within that federal agency. In their paper, Dr. Susan Czajkowski and colleagues (2019) describe how the NIH have developed into a rigorous advocate for the behavioral sciences; identifying priorities, allocating funding, and providing specialized peer-review panels to critically evaluate behavioral medicine science. The NIH's success has catalyzed other federal, non-profit, and private funding sources to develop similar frameworks to support all levels of projects and foci. Importantly, many successful behavioral medicine academics go on to have careers in these agencies and play instrumental roles in moving the field forward.

Scientific societies are another critical component of the profession's infrastructure. The American Psychosomatic Society, Society of Behavioral Medicine, Society for Health Psychology, and Academy of Behavioral Medicine Research serve as the professional core of the field in North America with many other societies and special interest groups serving complementary roles to the field. In his paper entitled, "The evolution of professional societies in behavioral medicine", Dr. Ken Freedland (2019) describes how these organizations provide both an umbrella for synergy as well as dissemination pathways such as conferences and peer-reviewed journals. He also describes the development of the Behavioral Medicine Research Council (BMRC) as the evolutionary next step in behavioral medicine professional societies. With representation and investment from the four major societies, along with federal and non-profit stakeholder buy-in, the BMRC aims to focus the collective expertise of the field to solve critical public health challenges. In 40 years, we may look back at the 2018 inaugural BMRC meeting as a second "Yale conference".

In addition to the broader organizational components, the behavioral medicine workforce is another critical part of the profession. With a sizeable and growing workforce in place, the field is now examining its makeup not only in terms of disciplinary but also demographic diversity. In particular, the past decade has seen growing awareness of the value of demographic diversity in scientific organizations (Kazdin, 2016). This movement is driven by both egalitarian motives and by the idea of inclusive excellence: recognition that the field's success is dependent on how well it includes and values diversity in all respects. Several recent reports document disparities in racial/ethnic representation in the broader biomedical workforce including in general representation, by rank, and by odds of research funding (c/f., Ginther et al., 2011; McGee, Saran, \& Krulwich, 2012). In this special series, Drs. Yoon, Falzon, Anderson, and Davidson (2019) provide an analysis of racial/ethnic and gender diversity representation trends in behavioral medicine from 1980 to 2018. Their paper describes how the field has grown more diverse over time yet remains critically underrepresented relative to national demographics. If the field does believe its future and success is tied to inclusivity, then active, sustained efforts are needed to prioritize that goal.

\section{Future directions}

Imagine the fields of medicine, psychology, and public health in their first 40 years. By comparison, behavioral medicine's developmental trajectory has been rapid, in part because it has integrated each of these fields and more into its universe. At age forty, the field of behavioral medicine has a mature professional infrastructure and workforce and is poised to contribute in a substantive and lasting manner to the promotion of human health. Welcome to the golden age!

\section{Compliance with ethical standards}

Conflict of interest John M. Ruiz and Christopher R. France declare that they have no conflict of interest.

Human and animal rights and Informed consent All procedures followed were in accordance with ethical standards of the responsible committee on human experimentation (institutional and national) and with the Helsinki Declaration of 1975, as revised in 2000. Informed consent was obtained from all patients for being included in the study.

\section{References}

Arigo, D., Jake-Schoffman, D. E., Wolin, K., Beckjord, E., Hekler, E. B., \& Pagoto, S. L. (2019). The history and future of digital health in the field of behavioral medicine. Journal of Behavioral Medicine. https://doi.org/10.1007/s10865-018-9966-z.

Christensen, A. J. (2019). Looking back, looking forward: Forty years of the Journal of Behavioral Medicine. Journal of Behavioral Medicine. https://doi.org/10.1007/s10865-018-9959-y.

Czajkowski, S. M., Riley, W. T., Stoney, C. M., Klein, W. M. P., \& Croyle, R. T. (2019). Key milestones during 40 years of behavioral medicine at the National Institutes of Health. Journal of Behavioral Medicine. https://doi.org/10.1007/s10865-0189981-0.

Emmons, K. (2019). Translating behavioral medicine evidence to public policy. Journal of Behavioral Medicine. https://doi.org/ 10.1007/s10865-018-9979-7. 
Freedland, K. E. (2019). The evolution of professional societies in behavioral medicine. Journal of Behavioral Medicine. https:// doi.org/10.1007/s10865-018-9946-3.

Ginther, D. K., Schaffer W. T., Schnell, J., Masimore, B., Liu, F., Haak, L. L., et al. (2011). Race, ethnicity, and NIH research awards. Science, 333, 1015-1019.

Kazdin, A. E. (2016). Editor's introduction for the special series: Diversity science. Clinical Psychological Science, 4, 699-700.

Larkin, K. T., Bridges, A. J., Fields, S. A., \& Vogel, M. (2016). Acquiring competencies in integrated behavioral health care doctoral, internship, and postdoctoral programs. Training and Education in Professional Psychology, 10, 14-23.

McGee, R., Jr., Saran, S., \& Krulwich, T. A. (2012). Diversity in the biomedical research workforce: Developing talent. Mt. Sinai Journal of Medicine, 79, 397-411.

Schneiderman, N., McIntosh, R., \& Antoni, M. (2019). Psychosocial risk and management of physical diseases. Journal of Behavioral Medicine. https://doi.org/10.1007/s10865-018-00007-y.
Wallston, K. A. (2019). Historical perspective on behavioral medicine's success in bringing different disciplines to the table. Journal of Behavioral Medicine. https://doi.org/10.1007/s10865018-9977-9.

Weiss, S. M., \& Schwartz, G. E. (2019). Behavioral Medicine: A retro, prospective view of the field. Journal of Behavioral Medicine. https://doi.org/10.1007/s10865-018-9960-5.

Yoon, S., Falzon, L., Anderson, N. B., \& Davidson, K. W. (2019). A look at the increasing demographic representation within behavioral medicine. Journal of Behavioral Medicine. https:// doi.org/10.1007/s10865-018-9983-y.

Publisher's Note Springer Nature remains neutral with regard to jurisdictional claims in published maps and institutional affiliations. 